\title{
Mechanisms of obtaining secondary structures on friction surface of experimental aluminum alloys for monometallic journal bearings
}

\author{
Pavel Podrabinnik ${ }^{1, *}$, Iosif Gershman ${ }^{1,2}$, Alexander Mironov ${ }^{1,2}$ and Ekaterina Kuznetsova ${ }^{1}$ \\ 1 Moscow State University of Technology «STANKIN», Vadkovsky lane 3a, 127055 Moscow, Russia; \\ p.podrabinnik@stankin.ru (P.P.); isgershman@gmail.com (I.G.); lecast@stankin.ru (A.M.) \\ evkuznetsova11@gmail.com (E.K.) \\ 2 Railway Research Institute JSC “VNIIZHT”, $3^{\text {rd }}$ Mytischinskaya Street 10, 107996 Moscow, Russia. \\ * Correspondence: p.podrabinnik@stankin.ru; Tel.: +7-499-972-9494
}

\begin{abstract}
Within the task of replacing bronze journal bearings with aluminum the processes taking part on friction surface of high-alloyed aluminum alloys working with steel are investigated. The surface and subsurface layer of experimental aluminum bearings were studied before and after tribological tests by scanning electron microscopy including energy-dispersive analysis. Both structural and composition changes in surface layer are shown. It has been revealed that secondary structures are formed on the surface during friction process and include all the chemical elements of the tribosystem which is a consequence of its self-organization. The interaction behavior of some chemical elements of tribological system is discussed.
\end{abstract}

Keywords: aluminum alloys; bronze; journal bearings; tribological alloys; friction; friction surface; secondary structures; self-organization.

\section{Introduction}

Today the most of cast monometallic journal bearings are made of antifriction bronzes of various grades. On railway transport the most common is bronze BrO4Z4S17 (closest analogue C83800 Brass according to ASTM B271, B505, B584) due to its mechanical and tribotechnical properties, which consumes more than 1.5 thousand tons of bronze per year. The task of increasing the economic efficiency of the production and operation of bearings always remains relevant, given the relatively high cost of copper, the main component of bronze. In this connection, the problem of replacing monometallic bronze journal bearings with bearings based on aluminum alloys is solving [1-7]. The transition from bronze to aluminum alloys is economically advantageous - aluminum is 3 times lighter than copper, and one kilogram of aluminum alloy is 2.5 to 2.7 times cheaper than bronze. Aluminum alloys are more fusible and, consequently, their smelting is less energy-consuming and takes less time, which makes it $15-20 \%$ cheaper. At the same time mechanical processing of bronze is 10 to $12 \%$ more expensive comparing to aluminum alloys.

The first works on the study of aluminum journal bearings have shown that multicomponent aluminum alloys can outperform the bronze in tribotechnical characteristics and have the potential to achieve the required mechanical properties $[2,8]$. The advantages of such aluminum alloys over bronze BrO4C4S17 in tribological properties are associated with a greater ability to self-organization of complex alloyed aluminum alloy and the formation on its surface a layer of protective secondary structures different from the initial state of the material $[4,6,9]$. For a more detailed understanding of the friction process, it is necessary to establish the principles of elements interaction in the system for the secondary structures formation on the aluminum alloy surface. There is an approach in which the selection of optimal sliding bearings is based on the principle of their least wear by introducing solid inclusions: carbides, oxides and nitrides [10]. The disadvantage of this approach is 
the complete disregard of the wear intensification of the counterbody, which is the more expensive steel shaft.

\section{Materials and Methods}

Eight experimental cast aluminum alloys were used in the study. The composition of each alloy included tin, lead, copper, silicon, magnesium and zinc as alloying components. The strength tests were carried out in accordance with GOST 1497-84 on cylindrical samples with an estimated length of $30 \mathrm{~mm}$ and a diameter of $6 \mathrm{~mm}$ on an electromechanical test machine "Instron" (USA). Tribotechnical tests were carried out using a friction machine "SMC-2" with a loading device up to $3000 \mathrm{~N}$. The composition control of each alloy after casting was performed by emission spectrometer Spectrolab-S (USA). The study of the initial state, friction surfaces and secondary structures of experimental alloys was performed on a Scanning Electron Microscope (SEM) "Tescan Vega 3" (Czech Republic) equipped with an Oxford Instruments (UK) energy-dispersive analysis (EDX) module. Before being placed in a microscope, the friction surfaces of the samples were rubbed with alcohol and dried, the cross-sections were further polished to remove the oxide film. All samples were examined at three magnifications: 100, 500 and 5000 times using secondary and back-scattered electron detectors. For each of the specimen studied, EDX was used to compile maps of chemical elements distribution, the distribution of elements along the line, and also the elemental composition in local areas of $1 \mu \mathrm{m}^{2}$.

\section{Results and discussion}

Of the 8 experimental alloys, the AO-5.8 alloy was chosen because of the lowest wear rates of both the alloy and the steel counterbody: 0.4 and $0.6 \mathrm{mg}$, respectively, during the test period. The composition of the alloy AO-5.8 is shown in Table 1. The presence of oxygen and carbon on the surface of the alloys of the initial samples, detected by EDX, is caused by the presence of residues of polishing components like suspensions and the onset of the oxidation process.

Table 1. AO-5.8 Elements composition.

\begin{tabular}{|c|c|c|c|c|c|c|c|c|c|c|c|c|c|}
\hline \multirow{2}{*}{ Object } & \multicolumn{13}{|c|}{ Elements composition, $\%$ mass. } \\
\hline & Al & Sn & $\mathrm{Pb}$ & $\mathrm{Cu}$ & $\mathrm{Zn}$ & Si & Mg & $\mathrm{Ti}$ & $\mathrm{C}$ & O & $\mathrm{Fe}$ & $S$ & Ca \\
\hline As cast & 82.1 & 5.8 & 2.7 & 4.1 & 2.3 & 1.5 & 1.5 & - & - & - & - & - & - \\
\hline Initial surface & 77.7 & 3.7 & 2.1 & 2.9 & 2.2 & 1.8 & 0.3 & 0.1 & 5.1 & 3.9 & 0.1 & - & - \\
\hline Friction surface & 40.5 & 3.9 & 4.7 & 2.0 & 1.5 & 0.4 & 0.6 & - & 31.4 & 14.5 & 0.3 & - & 0.1 \\
\hline \multicolumn{14}{|c|}{ Local spectra analysis } \\
\hline Al matrix & 72.1 & - & - & 0.8 & 1.3 & 0.2 & 0.2 & - & 14.3 & 10.8 & - & - & 0.2 \\
\hline $\mathrm{Pb}$ inclusion & 0.5 & 1.7 & 71.8 & 1.3 & 1.0 & 0.2 & 0.2 & - & 20.1 & 3.1 & - & 0.2 & - \\
\hline Sn inclusion & 1.5 & 23.5 & 16.8 & - & 1.0 & 0.1 & 5.8 & - & 20.2 & 30.5 & - & - & 0.5 \\
\hline
\end{tabular}

The friction surface of the alloy after 40 hours of run-in significantly differs from the initial one both in structure (Figure 1a, b) and in the qualitative elemental composition (Table 1). The result of these changes was the formation of secondary structures on the friction surface of the alloy. The formation of such secondary structures is a complex process of self-organization of the friction pair, in which all the objects of the tribosystem are involved: the bearing, the counterbody and the lubricant. In this case, the data given in Table 1, are the average values over a visible area of $0.553 \times$ $0.553 \mathrm{~mm}$. However, the process of friction at the micro level can be represented as the friction of a number of separate local areas, different in mechanical and chemical properties. Thus, various conditions are locally provided for the formation of secondary structures, and as a result, their composition can differ significantly from one structural zone to another. Complex multicomponent alloying firstly, allows increasing the strength of the aluminum matrix, making it possible to use for 
monometallic bearings production. Secondly, the introduction of such elements as tin and lead leads to an improvement in tribotechnical properties. Tin in the solid state in aluminum is practically insoluble and is present in the aluminum alloy in the form of soft structural constituents.
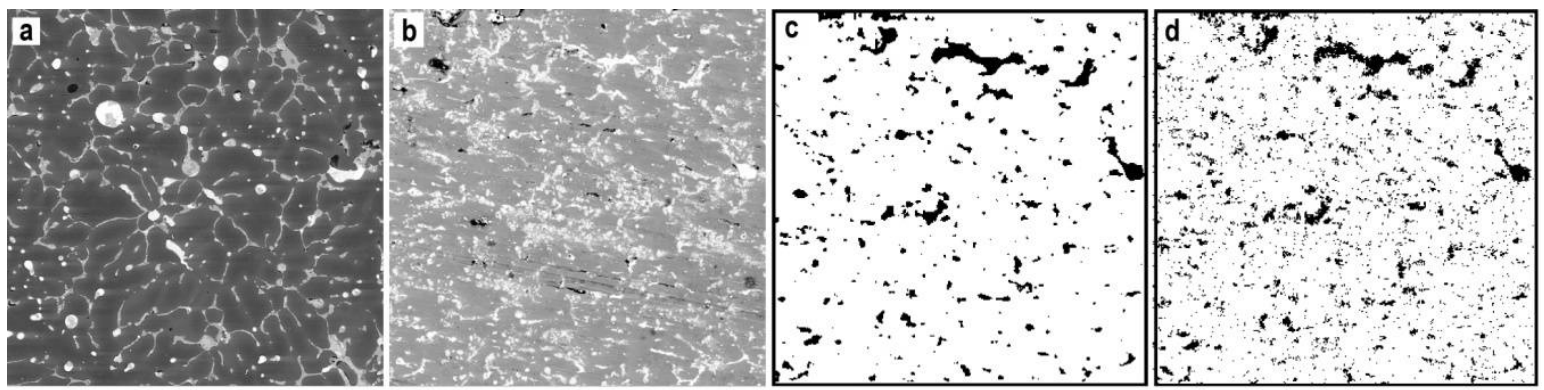

$100 \mu \mathrm{m}$

Figure 1. AO-5.8 alloy surface, where: (a) SEM image of surface structure before friction; (b) SEM image of surface structure after friction; (c) tin distribution map (EDX) on the friction surface; (d) calcium distribution map (EDX).

The distribution maps of elements (Fig. 1c, d) on the friction surface of the alloy demonstrate that the formation of secondary structures in a number of cases is not accidental. For all samples of the experimental alloys, a match was found between the pairs of lead and sulfur elements, tin and calcium. In both cases, the alloy component reacted with the element from the lubricant, forming more stable compounds. Thus, the lubricant is able to decompose into components during operation period, some of which react with the alloy elements, the other part with the steel elements. These same processes explain six times the amount of carbon increased on the friction surface and five times that of oxygen. As a consequence, the secondary structures are metal-polymer films of different composition on the friction surface $[9,11]$.

Tin is capable of spreading over a considerable area during friction due to its ductility and fusibility, thus contributing to the mass transfer of other elements such as lead, which forms a low-melting eutectic with tin, and zinc, which increases the strength of this eutectic and its tribological properties $[12,13]$. This process, in turn, increases the localization of the formation of thin lead films capable of actively interacting with fatly acids and non-metals in the composition of lubricants to form lead soaps, acting like solid lubricant.

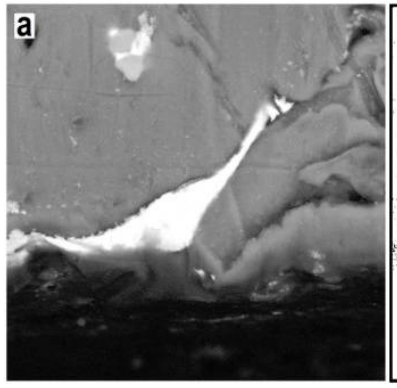
(b) tin distribution map (EDX) on the friction surface; (c) calcium distribution map (EDX); (d) potassium distribution map (EDX).

Copper, which is introduced into the alloy to increase strength, forms a solid solution with aluminum, and is also present in the alloy as solid intermetallic inclusions of $\mathrm{CuAl}_{2}$ [14]. During the run-in process, such inclusions as well as silicon ones, wear out more slowly than the aluminum matrix, realizing the Charpy principle on the surface and forming a beneficial oil-retaining microrelief, which also contributes to the formation of secondary structures. This makes it possible to increase score resistance due to cutting of the adhesion foci with steel, but at the same time its 
114

115

116

117

118

119

120

121

122

123

124

125

126

127

128

129

130

131

132

133

134

135

136

137

138

139

wear is increased due to a more intensive transfer of iron-containing particles to the surface. This explains the increased iron content on the friction surface of the alloy.

In the subsurface layer of the alloy, the changes occur to a depth of up to $100 \mu \mathrm{m}$. In Figure $2 \mathrm{a}$ area of the aluminum matrix is seen with an outlet of tin inclusion to the surface. According to the geometry of the cavity containing it, this outlet was provoked by plastic deformation of the surface layer and a physical decrease in the volume of the cavity, leaving, thus, the only possible direction for the output of the inclusion. However, it has been revealed that the components of a semidecomposed lubricant are able to form compounds not only on the friction surface, but also to penetrate through diffusion depthward to the alloy (Figure 2b, c, d). First of all, this is true for tin, calcium and potassium, as well as for a pair of lead-sulfur.

To determine the relative changes in the elements of the bearing material versus depth of penetration, an energy-dispersive analysis along the line was performed (Figure 3). The distribution character of curves changes depending on the local area is being analyzed (Figure $3 b, c)$. In the area without inclusions, aluminum, the main component of the matrix, gradually wears out during the friction process (Fig. 3b). Aluminum-depleted layer is about 5-7 micrometers. The same character of the distribution curves has the majority of alloying components, for example, zinc (Figure 3b). Although it is obvious that its content on the surface is higher relative to the matrix in which it is predominantly dissolved than in the initial state. The content of copper in the subsurface layer increases sharply. This is probably due to the difference in the wear rate of the softer aluminum matrix and copper inclusions: aluminum wears out more per time unit, increasing the proportion of copper in the total composition of the subsurface layer. A small tendency toward an increase in content, accompanied by a preliminary weak decrease, is shown by tin and, as a consequence, its satellites: calcium and potassium. Just an increase in concentration would mean that tin could be deposited from other sites by "smearing" the surface. However, the presence of a depleted region on the graph allows us to infer the forced transfer ("pumping") of this element from the subsurface layer to the friction surface.
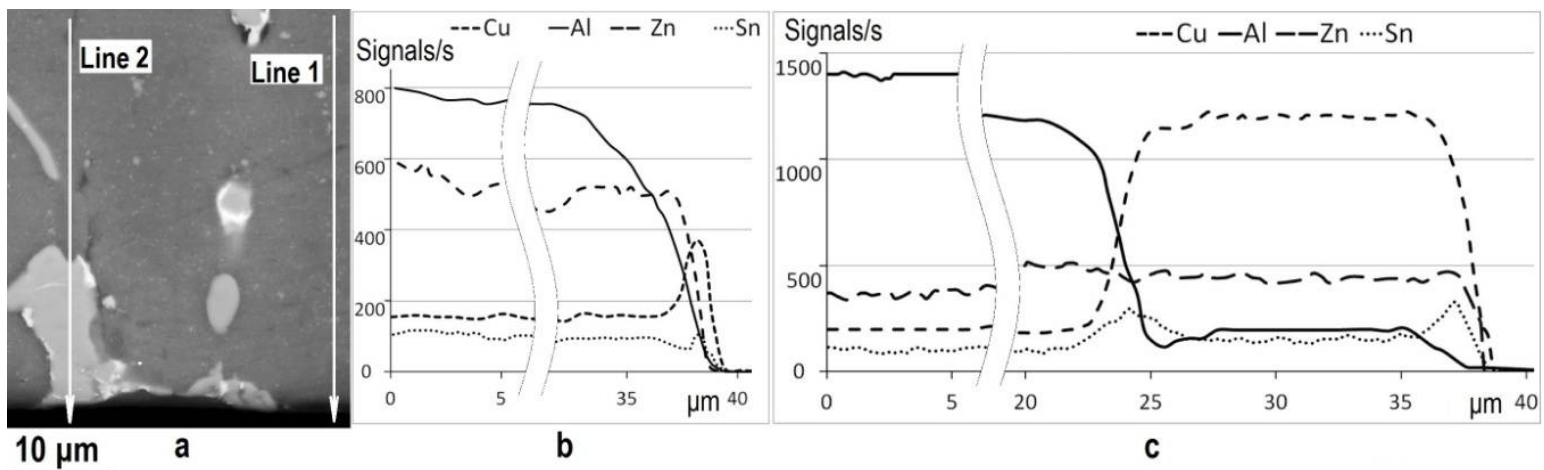

Figure 2. AO-5.8 alloy elements distribution depthward: (a) elements distribution along line 1; (b) elements distribution along line 2.

Tin directly in the form of inclusions on the straight line being analyzed is absent, but there are areas enriched by this element at the boundary of the aluminum matrix and copper inclusion, and also in the region where this inclusion enters the friction surface. Thus, the increased content of copper-based solid sections is accompanied by a more intense formation of secondary structures containing tin on them. Solid inclusions can increase the hardness of the alloy due to its mechanical properties, while in the process of friction they also act as abrasive particles, which increase the wear of the steel counterweight and increase the coefficient of friction. Tribosystem in the process of self-organization minimizes these negative aspects of friction by forming secondary structures that include tin alloy and lubricant components: polymer base, calcium, potassium. The thickness of such a film is less than $1 \mu \mathrm{m}$, so that electrons from scanning microscope, reaching the formations under the secondary structures, allow recording the base signal. 


\section{Conclusions}

During the run-in, the friction surface undergoes not only structural changes, but also component composition changes by the formation of profitable secondary structures. In their formation, to various degrees, all the objects of the tribosystem are involved, and the secondary structures themselves differ in composition in different sections of the alloy. Thus, the manufactured bearing is a "workpiece", the final processing of which before the output to the operating parameters during the friction process is carried out at the stage of running-in with the flow of self-organization processes. The variety of alloying components determines the freedom degree of the tribosystem for the formation of secondary structures.

This section is not mandatory, but can be added to the manuscript if the discussion is unusually long or complex.

Funding: This research was funded of Ministry of Education and Science of Russian Federation within the Agreement on grant № 14.574.21.0179 of September 26. 2017, unique identification number RFMEFI57417X0179.

Author Contributions: conceptualization, I.G. and A.M.; methodology, P.P. and A.M.; validation, P.P., A.M. and E.K.; formal analysis, A.M.; investigation, P.P.; resources, E.K, P.P. and A.M; data curation, E.K.; writing-original draft preparation, P.P.; writing-review and editing, I.G. and A.M.; visualization, P.P.; supervision, I.G. and A.M.; project administration, I.G. and E.K.

Conflicts of Interest: The authors declare no conflict of interest.

\section{References}

1. Lu, Z. C.; Gao, Y.; Zeng, M.Q. Improving Wear performance of dual-scale Al -Sn alloys. The role of Mg addition in enhancing Sn distribution and tribolayer stability. Wear 2014, 309, 216-225, DOI: 10.1016/j.wear.2013.11.018.

2. Stolyarova, O.O. et al. Investigation of tribological properties and structure of new aluminum bearing alloys. Materialovedenie 2014, № 8, 12-17 (in Russian).

3. Belov, N.; Mironov, A. et al. Aluminum alloys for antifriction applications, 1st ed.; MISIS: Moscow, Russia, 2016; 222 p., ISBN: 978-5-906848-22-8.

4. Mironov, A.E.; Gershman, I.S. et al. Aluminum casting antifriction alloys with increased capacity to adaptability of friction surfaces. Vestnik «VNIIZhT» 2017, 76, 336-340, DOI: 10.21780/2223-9731-2017-76-6-336-340.

5. Babu, M.V.; Rama Krishna, A.; Suman, K.N.S. Review of Journal Bearing Materials and Current Trends. Am. J. Mater. Sci. Technol. 2015, 2, 72-83. DOI: 10.7726/ajmst.2015.1006.

6. Fox-Rabinovich, G; Veldhuis, S.C. et al. Features of self-organization in ion modified nanocrystalline plasma vapor deposited AlTiN coatings under severe tribological conditions. J. Appl. Phys. 2007, 102 (7), DOI: $10.1063 / 1.2785947$.

7. Rusin, M; Skorentsev, A.L.; Kolubaev, E.A. Dry friction of pure aluminum against steel. J Frict. Wear+ 2016, 37 (1), 109-118, DOI: 10.3103/S1068366616010141.

8. Österreicher, J.A.; Papenberg, N.K. et al. Quantitative prediction of the mechanical properties of precipitation-hardened alloys with special application to Al-Mg-Si. Mater. Sci. Eng. A. 2017, 703, 380-385. DOI: 10.1016/j.msea.2017.07.080

9. Lu, Z.C.; Zeng, M.Q. et al. Improving wear performance of $\mathrm{CuSn}_{5} \mathrm{Bi}_{5}$ alloys through forming self-organized graphene/Bi nanocomposite tribolayer Wear 2016, 364-365, 122-129. DOI: 10.1016/j.wear.2016.07.014.

10. Gorlenko, A.O.; Davydov, S.V.; Erokhin, A.N. Tribodiagnostics spherical plain bearings. Handbook. An Eingineering Journal 2017, 9-13. DOI: 10.14489/hb.2017.12.pp.009-013.

11. Piskarev, A.S.; Sil'chenko, O.B. et al. Analysis of structural solutions at design of high-loaded sliding bearings with liquid lubricants. Vestnik Mashinostroeniya 2018, 5, 37-43.

12. Springer, H.; Szczepaniak, A.; Raabe, D. On the role of zinc on the formation and growth of intermetallic phases during interdiffusion between steel and aluminium alloys. Acta Mater. 2015, 96, 203-211. DOI: 10.1016/j.actamat.2015.06.028. 
13. Kiran, T.S. et al. Effect of heat treatment on tribological behavior of zinc aluminum alloy reinforced with graphite and SIC particles for journal bearing. Ind. Lubr. Tribo. 2015, 67, 292-300. DOI: 10.1108/ilt-08-2013-0090.

14. Menshikova, S.G.; Shirinkina, I.G. et al. A study of the structure and properties of aluminum alloys with copper produced under superfast cooling of melt. Met. Sci. Heat. Treat+ 2018, 3, 45-52. 